\title{
Mycobacterium mageritense sp. nov. $\dagger$
}

\author{
P. DOMENECH, ${ }^{1} \ddagger$ M. S. JIMENEZ,${ }^{2}$ M. C. MENENDEZ, ${ }^{1}$ T. J. BULL, ${ }^{3}$ S. SAMPER, ${ }^{4}$ A. MANRIQUE ${ }^{2}$ \\ AND M. J. GARCIA ${ }^{1 *}$
}

Departamento de Medicina Preventiva, Facultad de Medicina, Universidad Autonoma de Madrid, 28029 Madrid, ${ }^{1}$ Centro Nacional de Microbiologia, Virologia e Inmunologia Sanitarias, Instituto de Salud Carlos III, Majadahonda, Madrid, ${ }^{2}$ and Departamento de Microbiologia, Facultad de Medicina, Universidad de Zaragoza, 50009 Zaragoza, ${ }^{4}$ Spain, and Department of Surgery, St. Georges Hospital Medical School, London SW17 ORE, United Kingdom ${ }^{3}$

\begin{abstract}
Strains of a new species of rapidly growing, nonphotochromogenic mycobacteria, Mycobacterium mageritense, were isolated from human sputum. The growth characteristics, acid fastness, and mycolic acids of the isolates were consistent with those of Mycobacterium species. The isolates were identified as members of a new species by performing a biochemical analysis and DNA-DNA hybridization experiments, and by comparing the sequences of several conserved genes, such as the $16 \mathrm{~S}$ rRNA, $h s p 65$, and sodA genes. A phylogenetic analysis in which 16S rRNA and sodA sequences were used identified $M$. mageritense as a novel distinct species and placed $M$. mageritense between members of the Mycobacterium fortuitum complex and the thermotolerant rapidly growing group. Our results demonstrate that the taxonomic value of sodA sequence analysis in the genus Mycobacterium is similar to the well-established value of $16 \mathrm{~S}$ rRNA sequence analysis.
\end{abstract}

Mycobacteria are aerobic, nonmotile bacteria that are widespread in nature and range from soil-dwelling saprophytes to pathogens of humans and animals $(10,36)$. In taxonomic studies of members of the Mycobacteriaceae workers have traditionally relied on biochemical and cultural characteristics (33, 34) together with analyses of fatty acid composition (8) to determine the identity of a new organism. The systematics of these organisms has been refined by techniques such as highperformance liquid chromatography (7), multilocus enzyme electrophoresis (21), DNA-DNA hybridization, and phylogenetic classification based on the evolutionary sequence diversity of one or more universally present genes (26). The most commonly used gene for phylogenetic studies has been the $16 \mathrm{~S}$ rRNA gene; however, the inability of $16 \mathrm{~S}$ rRNA gene data to distinguish some closely related species (1) has suggested that other conserved genes, such as hsp65 (31) and $\operatorname{sod} A(5,38)$ should be used. The current general recommendations for descriptions of new mycobacterial species include the need for at least DNA-DNA hybridization, biochemical, and cultural studies to show significant differences from previously described clusters of organisms (15).

Mycobacterial strains that could not be identified by conventional identification procedures were isolated from human sputum specimens. Colonization of the respiratory tract was not associated with disease in all cases. In this paper we describe the results of a taxonomic study of these strains and propose a new species, Mycobacterium mageritense.

\section{MATERIALS AND METHODS}

Bacterial strains. Five new strains were studied. Two of these strains (strain $938^{\mathrm{T}}$ [ $\mathrm{T}=$ type strain] and 1336 ) were received in 1987 from the Hospita Cantoblanco in Madrid, Spain; two (strains 1635 and 1636) were received from the same hospital in 1989; and one (strain 1470) was received in 1987 from the Hospital Santa Marina in Pais Vasco, Spain. All of the strains were recovered from sputum specimens from different patients. In addition, we studied the

* Corresponding author. Mailing address: Departamento de Medicina Preventiva, Facultad de Medicina, Universidad Autonoma de Madrid, st/ Arzobispo Morcillo, 4, 28029 Madrid, Spain. Phone: 34-1397 5440. Fax: 34-1-397 5353. E-mail: mjgarcia@mvax.fmed.uam.es.

† This paper is dedicated to the memory of Ana Manrique.

$\ddagger$ Present address: Département de Génétique Moléculaire Bactérienne, Institut Pasteur, Paris, France. following previously described mycobacterial strains: Mycobacterium abscessus ATCC $19977^{\mathrm{T}}$ (American Type Culture Collection), Mycobacterium agri CIPT $1320001^{\mathrm{T}}$ (Collection Institut Pasteur Tuberculose), Mycobacterium aurum L1 (11), Mycobacterium brumae CIPT $103465^{\mathrm{T}}$, Mycobacterium chelonae ATCC $35752^{\mathrm{T}}$, Mycobacterium chitae CIPT 116000 , Mycobacterium fortuitum ATCC $6841^{\mathrm{T}}$, Mycobacterium gadium ATCC $27726^{\mathrm{T}}$, Mycobacterium gilvum Standford 132, Mycobacterium mucogenicum 283 (laboratory-isolated strain), Mycobacterium peregrinum ATCC $14467^{\mathrm{T}}$, Mycobacterium phlei IMRU 500 (Institute of Microbiology, Rutgers University), Mycobacterium porcinum ATCC $27406^{\mathrm{T}}$, Mycobacterium senegalense NCTC $10956^{\mathrm{T}}$ (National Collection of Type Cultures), and Mycobacterium smegmatis CIPT $141330010^{\mathrm{T}}$. Nocardia asteroides (Centro Nacional de Microbiologia Virologia e Inmunologia Sanitarias) was also studied.

Characterization of strains. Standard methods were used to isolate mycobacteria from clinical specimens (24). Colony morphology and the ability to grow at various temperatures $\left(22,30,37\right.$, and $\left.45^{\circ} \mathrm{C}\right)$, pigment production, and photoreactivity were determined after 2 weeks of incubation on Löwenstein-Jensen slants.

The following properties were determined as described previously: nitrate reductase, arylsulfatase, urease, nicotinamidase, pyrazinamidase, allantoinase, benzamidase, iso-nicotinamidase, succinamidase (32), and catalase (34) activities, resistance to sodium chloride, and hydrolysis of Tween 80 (33). Tests to determine iron uptake and utilization of citrate, mannitol, and inositol as sole carbon sources were performed by using the procedure of Silcox et al. (23). Growth in the presence of isoniazid $(0.2$ and $1.0 \mu \mathrm{g} / \mathrm{ml})$, ethambutol $(1.5$ and 2.0 $\mu \mathrm{g} / \mathrm{ml}$ ), cycloserine (30 and $40 \mu \mathrm{g} / \mathrm{ml})$, capreomycin $(40 \mu \mathrm{g} / \mathrm{ml})$, thiosemicarbazone $(20 \mu \mathrm{g} / \mathrm{ml})$, and thiophen-2-carboxylic acid hydrazide $(10 \mu \mathrm{g} / \mathrm{ml})$ was determined as described previously (6)

Analyses of mycolic acids were performed by one-dimensional thin-layer chromatography as described previously (2).

Catalase activity gels. The protein extracts used for nondenaturing polyacrylamide gel electrophoresis (ND-PAGE) on $10 \%(\mathrm{wt} / \mathrm{vol})$ polyacrylamide gels were prepared as described previously $(4,37)$. The catalase and peroxidase activities of mycobacterial extracts were examined by the double-staining method as described previously (35). Thermolabile and thermostable enzymes were distinguished by heat treating extracts at $68^{\circ} \mathrm{C}$ for $1 \mathrm{~min}$ before the ND-PAGE gels were electrophoresed.

DNA extraction. Bacterial strains were grown in $100-\mathrm{ml}$ Dubos-Tween-albumin (DTA) broth (Difco Laboratories) cultures. Extraction and purification of DNA were carried out as described previously (9). Briefly, cultures were incubated with D-cycloserine for 24 to $48 \mathrm{~h}$. Cells were then lysed with lysozyme (4 $\mathrm{mg} / \mathrm{ml})$, proteinase $\mathrm{K}(50 \mu \mathrm{g} / \mathrm{ml})$, and sodium dodecyl sulfate $(1 \%)$, and the extracts were purified by phenol-chloroform and ethanol precipitation. DNA concentrations were estimated by UV absorbance, and then the preparations were stored in ethanol at $-20^{\circ} \mathrm{C}$.

Nucleic acid analysis. (i) PCR-RFLP analysis of the heat shock protein gene (hsp65). A two-step assay in which a PCR was followed by a restriction fragment length polymorphism (RFLP) analysis was used to compare our strains with other rapidly growing mycobacterial species, as described by Telenti et al. (31). Amplified products were digested with restriction enzymes BstEII and HaeII (Boehringer-Mannheim) in separate reactions and then were separated by horizontal electrophoresis by using NuSieve agarose (FMC Bioproducts) gels. Fragments were visualized by ethidium bromide staining and exposure to UV light 
TABLE 1. Distinguishing characteristics of $M$. mageritense and related rapidly growing mycobacteria ${ }^{b}$

\begin{tabular}{|c|c|c|c|c|c|c|c|}
\hline Characteristic & M. mageritense ${ }^{c}$ & M. chitae & M. confluentis & M. fortuitum & M. peregrinum & M. senegalense & M. smegmatis \\
\hline Smooth colonies & 100 & $+^{a}$ & + & + & $+1-$ & - & + \\
\hline Pigmentation & 0 & - & - & - & - & - & - \\
\hline \multicolumn{8}{|l|}{ Growth at: } \\
\hline $30^{\circ} \mathrm{C}$ & 100 & + & + & + & + & + & + \\
\hline $37^{\circ} \mathrm{C}$ & 100 & + & + & + & + & + & + \\
\hline $45^{\circ} \mathrm{C}$ & 80 & - & - & - & - & - & + \\
\hline \multicolumn{8}{|l|}{ Growth on: } \\
\hline $5 \% \mathrm{NaCl}$ & 80 & $+1-$ & - & + & + & + & + \\
\hline MacConkey agar without crystal violet & 100 & - & & + & + & & - \\
\hline Iron uptake & 40 & $+1-$ & - & + & + & - & + \\
\hline \multicolumn{8}{|l|}{ Enzymatic activities } \\
\hline Nitrate reductase & 70 & + & + & + & + & - & t \\
\hline Tween hydrolysis & 0 & & - & + & + & & + \\
\hline Arylsulfatase (3 days) & 80 & - & & + & + & + & - \\
\hline Urease & 60 & & + & + & + & & + \\
\hline Catalase $\left(68^{\circ} \mathrm{C}\right)$ & 0 & & + & + & + & + & + \\
\hline Nicotinamidase & 100 & & + & + & - & & \\
\hline Pyrazinamidase & 100 & & + & + & + & & \\
\hline Allantoinase & 60 & - & & + & + & + & + \\
\hline Benzamidase & 60 & - & - & - & - & + & $+1-$ \\
\hline Iso-nicotinamidase & 40 & - & - & - & - & + & $+1-$ \\
\hline Succinidamidase & 80 & - & - & - & - & & + \\
\hline \multicolumn{8}{|l|}{ Acid produced from: } \\
\hline Citrate & 40 & - & & $+1-$ & $+1-$ & + & + \\
\hline Mannitol & 100 & - & & - & + & & + \\
\hline Inositol & 80 & & & - & - & & + \\
\hline \multicolumn{8}{|l|}{ Resistance to } \\
\hline Isoniazid & 100 & & $\mathrm{~S}$ & $\mathbf{R}$ & & & $\mathrm{R}$ \\
\hline Ethambutol & 80 & & $\mathrm{~S}$ & $\mathrm{R}$ & $\mathrm{R}$ & & $\mathrm{R}$ \\
\hline D-Cycloserine & 100 & & & & & & \\
\hline Capreomycin & 100 & & & $\mathrm{~S}$ & $\mathrm{~S}$ & $\mathrm{~S}$ & \\
\hline TSC & 100 & & & & & & \\
\hline $\mathrm{TCH}$ & 100 & & & $\mathrm{R}$ & $\mathrm{R}$ & & \\
\hline Mycolic acid type $^{d}$ & $\mathrm{I}, \mathrm{II}, \mathrm{V}$ & $\mathrm{I},(\mathrm{II}), \mathrm{V}$ & (I),IV & $\mathrm{I},(\mathrm{II}), \mathrm{V}, \mathrm{VII}^{e}$ & $\mathrm{I},(\mathrm{II}), \mathrm{V}, \mathrm{VII}^{e}$ & $\mathrm{I},(\mathrm{II}), \mathrm{V}, \mathrm{VII}$ & $\mathrm{I}, \mathrm{II}, \mathrm{V}$ \\
\hline
\end{tabular}

+ , positive; - , negative; +/-, variable; S, susceptible; R, resistant

${ }^{b}$ Biochemical data for rapidly growing mycobacterial species were obtained from references $12,14,23$, and 36 .

$c$ The values are the percentages of strains that are positive or resistant.

${ }^{d}$ Mycolic acid composition data for rapidly growing mycobacterial species were obtained from references $2,14,16$, and 17.

${ }^{e}$ Mycolic acid type VII is found in only some strains of $M$. fortuitum and $M$. peregrinum $(2,17)$.

$f$ TSC, thiosemicarbazone; TCH, thiophen-2-carboxylic acid hydrazide.

(ii) Amplification and sequencing of ribosomal DNA. Template DNAs from strains $938^{\mathrm{T}}, 1336,1635,1636$, and 1470 were produced by PCR by using oligonucleotide R1 (5'-CTCGGTCCTAGTTTGAGAGGTT-3'; positions 4 to 25 ) and biotinylated oligonucleotide R-c3 (5'-AAGGAGGTGATCCAGCCGCA$3^{\prime}$; positions 1522 to 1542 ) (positions correspond to positions on the Escherichia coli $16 \mathrm{~S}$ rRNA gene [29]). Each PCR mixture $(50 \mu \mathrm{l})$ was prepared by using 100 ng of genomic mycobacterial DNA and the following components: $50 \mu \mathrm{M} \mathrm{KCl}$ $10 \mathrm{mM}$ Tris- $\mathrm{HCl}(\mathrm{pH} 8.3), 1.5 \mathrm{mM} \mathrm{MgCl}, 200 \mu \mathrm{g}$ of gelatin per ml, $25 \mathrm{pmol}$ of $10 \mathrm{mM}$ Tris- $\mathrm{HCl}(\mathrm{pH} 8.3), 1.5 \mathrm{mM} \mathrm{MgCl}, 200 \mu \mathrm{g}$ of gelatin per $\mathrm{ml}, 25 \mathrm{pmol}$ of
each primer, each deoxynucleoside triphosphate at a concentration of $200 \mu \mathrm{M}$, and $0.8 \mathrm{U}$ of $P f u$ polymerase (Stratagene). The reaction mixtures were subjected to 39 cycles of amplification ( $1 \mathrm{~min}$ of denaturation at $94^{\circ} \mathrm{C}$ and $3 \mathrm{~min}$ of annealing and extension at $\left.68^{\circ} \mathrm{C}\right)(13)$. Template DNAs were purified by using Dynabead M-280-streptavidin (Dynal) and a Dynal model MPC-E magnetic separator as recommended by the manufacturer.

Sequencing reactions were performed by using T7 DNA polymerase (Sequenase, version 2.0; U.S. Biochemicals) as recommended by the manufacturer and $\alpha{ }^{35} \mathrm{~S}$-dATP as the label. The primers used to sequence $16 \mathrm{~S}$ rRNA were primers R4 (5'-GAGTGGGCAAGCAATGAGCTCA-3'; positions 98 to 117), R5 (5'-T GTGGGAGAGTCCGGCCGATGGGC-3'; positions 283 to 306 ), RAC8 (5'-C ACTGCTGCCTCCCGTAGG-3'; positions 341 to 359), Rc6 (5'-CGTATTACC GCGGCTGCTGGCAC-3'; positions 507 to 529$)$, and Rc2 (5'-GTGGACTAC
CAGGGTATCTAATCCT-3'; positions 784 to 808 ) (positions correspond to positions on the $E$. coli $16 \mathrm{~S}$ rRNA gene [29])

Sequencing reaction mixtures were resolved on $6 \%(\mathrm{wt} / \mathrm{vol})$ polyacrylamide gels containing $46 \%$ (wt/vol) urea. The gels were dried and exposed to X-ray film. The sequences of both strands were checked.

(iii) Amplification and sequencing of the superoxide dismutase gene (sodA) sodA gene sequences were determined as described previously (5). Briefly, cultures grown to purity on Löwenstein-Jensen slopes were washed in Tris-EDTA ( $\mathrm{pH} 8.0$ ), and DNAs were rapidly extracted for PCR by sequential freezethawing in liquid nitrogen and sonication at $30^{\circ} \mathrm{C}$. Primers ACATCTCGGGTC AGATCAACGACG and GACGTTCTTGTACTGCAGGTA were used to amplify a 464-bp product from these preparations in PCR mixtures containing 50 $\mu \mathrm{M} \mathrm{KCl}, 1.5 \mathrm{mM} \mathrm{MgCl} 2,10 \mathrm{mM}$ Tris ( $\mathrm{pH} 8.3$ ), $0.015 \%$ gelatin, each primer at a concentration of $2 \mu \mathrm{M}$, each deoxynucleoside triphosphate at a concentration of $200 \mu \mathrm{M}$, and $1 \mathrm{U}$ of $T a q$ polymerase (Promega). The amplification reaction consisted 30 cycles, with each cycle consisting of $94^{\circ} \mathrm{C}$ for $30 \mathrm{~s}, 60^{\circ} \mathrm{C}$ for $30 \mathrm{~s}$, and $72^{\circ} \mathrm{C}$ for $45 \mathrm{~s}$. Products of the expected sizes were then cleaned for sequencing by using Wizard columns (Promega). Sequences were obtained by using the FSTaq automated sequencing system (Perkin-Elmer) with a 60-ng product and a sequencing annealing temperature of $60^{\circ} \mathrm{C}$. The sequences of both strands were checked by using the primary amplification primers as sequencing primers 
TABLE 2. PCR-RFLP analysis of the gene encoding the $65-\mathrm{kDa}$ heat shock protein ${ }^{a}$

\begin{tabular}{lll}
\hline \multirow{2}{*}{ Species } & \multicolumn{2}{c}{ Size(s) of fragment(s) (bp) obtained with: } \\
\cline { 2 - 3 } & \multicolumn{1}{c}{ BstEII } & \multicolumn{1}{c}{ Hae III } \\
\hline M. mageritense & $85,140,245$ & $60,130,170$ \\
M. abscessus & 220,245 & 60,160 \\
M. chelonae & 140,325 & 210 \\
M. fortuitum & $80,125,245$ & 135,155 \\
M. peregrinum & 220,245 & $100,150,155$ \\
M. smegmatis & $85,120,245$ & 130,160 \\
\hline
\end{tabular}
31.

${ }^{a}$ Data for rapidly growing mycobacterial species were obtained from reference

DNA-DNA hybridization. DNA-DNA homology experiments were performed as described previously (9) by using our strains and other strains (see Table 3). Genomic DNAs from strains $938^{\mathrm{T}}, 1336,1470,1635$, and $1636(0.5 \mu \mathrm{g}$ each $)$ were labelled in vitro by using a nick translation labelling kit (BoehringerMannheim) and $30 \mu \mathrm{Ci}$ of $\left[\alpha^{-{ }^{32}} \mathrm{P}\right] \mathrm{dCTP}$ (Amersham).

Portions $(1 \mu \mathrm{g})$ of each unlabelled DNA were bound to nylon membrane filters (Amersham) by using alkaline denaturation and UV fixation. Hybridizations were carried out under stringent conditions for $40 \mathrm{~h}$. The filters were then washed and counted with a liquid scintillation counter (Beckman). The relative binding ratios for each strain were calculated from the counts of homologous DNA bound and were expressed as percentages.

RFLP analysis of 16S rRNA gene. An RFLP analysis of the 16S rRNA gene was performed to compare the new strains with other rapidly growing mycobacterial species, as described previously (9). Briefly, genomic DNAs were digested with restriction enzyme $B a m H I$. The digests were analyzed by gel electrophoresis on horizontal slabs containing $0.75 \%(\mathrm{wt} / \mathrm{vol})$ agarose, and they were Southern transferred to nylon membrane filters (Amersham).

An 804-bp fragment of the 16S rRNA gene of $M$. fortuitum ATCC $6841^{\mathrm{T}}$ was obtained by PCR and used as a probe. For DNA amplification we used the following oligonucleotides from the Mycobacterium bovis BCG 16S rRNA sequence: R-1 and R-c2 (see above). The amplification mixtures $(50 \mu \mathrm{l})$ used are described above. The cycling profile consisted 30 cycles, with each cycle consisting of $1 \mathrm{~min}$ at $94^{\circ} \mathrm{C}, 30 \mathrm{~s}$ at $58^{\circ} \mathrm{C}$, and $1 \mathrm{~min}$ at $72^{\circ} \mathrm{C}$, followed by a final incubation at $72^{\circ} \mathrm{C}$ for $5 \mathrm{~min}$. The ribosomal probe was labelled by using the prime- $\alpha$-gene system (Promega) and $20 \mu \mathrm{Ci}$ of $\left[\alpha^{-{ }^{3}} \mathrm{P}\right] \mathrm{dCTP}$.

Phylogenetic analysis. Sequences were aligned by using the CLUSTAL W program (22) with 388-bp sodA sequences between positions 193 and 585 (38) and 420-bp 16S rRNA sequences between positions 144 and 554 (E. coli numbering [29]). The sequences of strain $938^{\mathrm{T}}$ were aligned with the corresponding sequences of rapidly growing mycobacteria. For a phylogenetic sequence comparison between $16 \mathrm{~S}$ rRNA and sod $A$ sequences, 12 rapidly growing species and two slowly growing species were selected and their sequences were aligned separately.

The GenBank accession numbers for the 16S rRNA and sodA sequences used were as follows: $M$. abscessus, X82235 and U86082, respectively; $M$. aurum M29558 and U86084, respectively; $M$. chelonae, X82236 and Z48216, respectively; $M$. fortuitum, ATCC $6841^{\mathrm{T}}$, X52933 and X81385, respectively; $M$. fortuitum ATCC 49403, X65528 and U86085, respectively; $M$. fortuitum ATCC 49404 X65529 and U86086, respectively; $M$. gilvum, X55599 and U86083, respectively, $M$. mageritense, $\mathrm{X} 99838$ and $\mathrm{U} 73305$, respectively; $M$. mucogenicum, $\mathrm{X} 80771$ and U86089, respectively; $M$. peregrinum, X52921 and U86088, respectively; $M$. phlei, M29566 and Z48211, respectively; $M$. senegalense, M29567 and U86087, respectively; and M. smegmatis, X52922 and Z48214, respectively. The $N$. asteroides $16 \mathrm{~S}$ IRNA and sodA sequences (GenBank accession numbers M59056 and X81392, respectively) were used as the genus outgroup sequences, and the Mycobacterium tuberculosis 16S rRNA and sodA sequences (GenBank accession numbers X58890 and X52861, respectively) and the Mycobacterium avium 16S rRNA and sodA sequences (GenBank accession numbers X52918 and X81384, respectively) were used as the outgroup sequences for the slowly growing mycobacteria.

Weighted distance matrices were calculated by using the Jukes-Cantor method and DNADIST in the PHYLIP analysis package (22). Phylogenetic trees were constructed by using the FITCH algorithm program with global rearrangements and at least 20 random input orders.

\section{RESULTS AND DISCUSSION}

For the most part, the five new strains grew on LöwensteinJensen agar in eugonic, smooth, nonphotochromogenic colonies within 3 to 5 days at temperatures ranging from 22 to $45^{\circ} \mathrm{C}$; the only exception was strain 1636 , which did not grow at $45^{\circ} \mathrm{C}$. $M$. mageritense cells were strongly acid-alcohol fast and were predominantly long rods (length, 4 to $9 \mu \mathrm{m}$ ). Spores, capsules, and true branching were not observed.

The $M$. mageritense strains grew on common agar and on MacConkey agar without crystal violet. They did not produce a thermostable catalase, and they exhibited internal variability for biochemical characteristics such as urease, nitrate reductase, and arylsulfatase activities and the presence of several amidases (Table 1). These strains were resistant to most of the drugs tested, and they utilized mannitol and inositol as sole carbon sources. A comparison of the biochemical properties of $M$. mageritense and other rapidly growing mycobacterial species revealed that the highest levels of similarity were the levels of similarity to $M$. fortuitum (69\%) and $M$. smegmatis (63\%) (Table 1). Studies of the catalase and peroxidase activities of strains by ND-PAGE of protein extracts revealed the presence of a single band of heat-labile catalase at the same level for each of the strains (Fig. 1).

The mycolic acid compositions of mycobacteria have been studied extensively and have been shown by different methods $\begin{array}{llllllllllllllll}1 & 2 & 1 \mathrm{H} & 2 \mathrm{H}\end{array}$

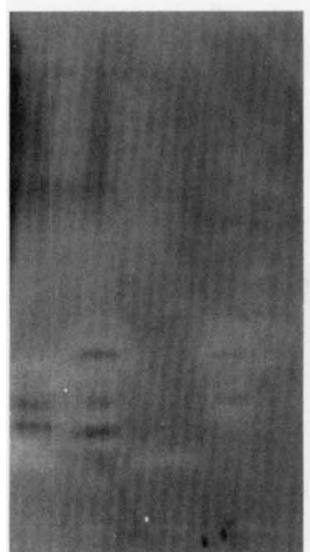

$\begin{array}{llllllllllllllll}3 & 3 \mathrm{H} & 4 & 4 \mathrm{H} & 5 & 5 \mathrm{H} & 6 & 6 \mathrm{H} & 7 & 7 \mathrm{H} & 8 & 8 \mathrm{H}\end{array}$

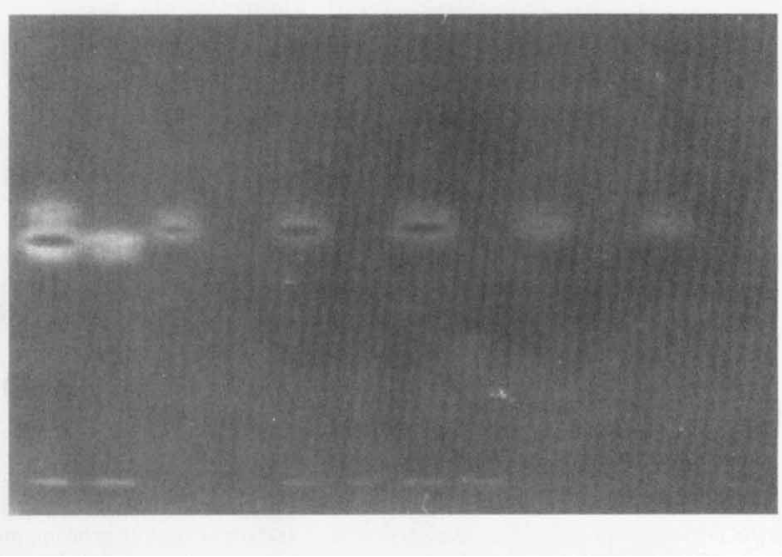

FIG. 1. ND-PAGE gels stained for catalase and peroxidase activities. Catalase activity appears as a white band, and peroxidase activity appears as a dark band. Protein extracts from the following strains were used: $M$. fortuitum ATCC $6841^{\mathrm{T}}$ (lanes 1 and $1 \mathrm{H}$ ), M. smegmatis CIPT $141330010^{\mathrm{T}}$ (lanes 2 and $2 \mathrm{H}$ ), M. peregrinum ATCC $14467^{\mathrm{T}}$ (lanes 3 and $3 \mathrm{H}$ ), M. mageritense $983^{\mathrm{T}}$ (lanes 4 and $4 \mathrm{H}$ ), M. mageritense 1336 (lanes 5 and $5 \mathrm{H}$ ), M. mageritense 1470 (lanes 6 and $6 \mathrm{H}$ ), $M$. mageritense 1635 (lanes 7 and $7 \mathrm{H}$ ), and $M$. mageritense 1636 (lanes 8 and $8 \mathrm{H}$ ). The extracts in lanes $1 \mathrm{H}, 2 \mathrm{H}, 3 \mathrm{H}, 4 \mathrm{H}, 5 \mathrm{H}, 6 \mathrm{H}, 7 \mathrm{H}$, and $8 \mathrm{H}$ were heat treated at $68^{\circ} \mathrm{C}$ for $1 \mathrm{~min}$. 
TABLE 3. Levels of DNA-DNA homolog between M. mageritense strains and other organisms

\begin{tabular}{|c|c|c|c|c|c|}
\hline \multirow{2}{*}{ Species or strain } & \multicolumn{5}{|c|}{$\%$ DNA-DNA homology with the following sources of labelled DNA ${ }^{a}$ : } \\
\hline & Strain $938^{\mathrm{T}}$ & Strain 1336 & Strain 1470 & Strain 1635 & Strain 1636 \\
\hline M. mageritense $938^{\mathrm{T}}$ & 100 & & & & \\
\hline M. mageritense 1336 & $73 \pm 8^{b}$ & 100 & & & \\
\hline M. mageritense 1470 & $>100$ & $>100$ & 100 & & \\
\hline$M$. mageritense 1635 & $69 \pm 2$ & $88 \pm 6$ & $97 \pm 2$ & 100 & \\
\hline M. mageritense 1636 & $86 \pm 3$ & $71 \pm 6$ & $73 \pm 5$ & $70 \pm 3$ & 100 \\
\hline M. abscessus ATCC $19977^{\mathrm{T}}$ & $13 \pm 1$ & $13 \pm 1$ & $7 \pm 1$ & $14 \pm 1$ & $6 \pm 1$ \\
\hline M. chelonae ATCC $35752^{\mathrm{T}}$ & $12 \pm 1$ & $8 \pm 1$ & $10 \pm 1$ & $9 \pm 1$ & $14 \pm 1$ \\
\hline M. chitae CIPT 116000 & $14 \pm 1$ & $14 \pm 1$ & $23 \pm 5$ & $26 \pm 1$ & $9 \pm 2$ \\
\hline M. fortuitum ATCC $6841^{\mathrm{T}}$ & $52 \pm 3$ & $37 \pm 4$ & $30 \pm 4$ & $35 \pm 1$ & $15 \pm 3$ \\
\hline M. gadium ATCC $27726^{\mathrm{T}}$ & $9 \pm 1$ & $12 \pm 4$ & $7 \pm 2$ & $9 \pm 2$ & $6 \pm 1$ \\
\hline M. mucogenicum 283 & $8 \pm 2$ & $5 \pm 2$ & $7 \pm 1$ & $8 \pm 5$ & $7 \pm 4$ \\
\hline M. peregrinum ATCC $14467^{\mathrm{T}}$ & $32 \pm 3$ & $48 \pm 3$ & $17 \pm 2$ & $32 \pm 5$ & $22 \pm 1$ \\
\hline M. porcinum ATCC $27406^{\mathrm{T}}$ & $16 \pm 1$ & $16 \pm 1$ & $6 \pm 1$ & $5 \pm 1$ & $19 \pm 1$ \\
\hline M. senegalense NCTC $10956^{\mathrm{T}}$ & $11 \pm 2$ & $11 \pm 2$ & $8 \pm 2$ & $6 \pm 2$ & $15 \pm 5$ \\
\hline M. smegmatis CIPT $141330010^{\mathrm{T}}$ & $16 \pm 4$ & $16 \pm 2$ & $28 \pm 1$ & $19 \pm 2$ & $23 \pm 1$ \\
\hline N. asteroides & $3 \pm 1$ & $3 \pm 1$ & $1 \pm 1$ & $3 \pm 1$ & $2 \pm 1$ \\
\hline
\end{tabular}

${ }^{a}$ The values are the levels of homology between $M$. mageritense labelled DNAs and unlabelled DNAs.

${ }^{b}$ Mean \pm standard deviation from four different experiments.

to be for the most part species specific $(8,14,17)$. An examination of the mycolic acids after methylation with diazomethane by one-dimensional thin-layer chromatography revealed the presence of $\alpha$-mycolate, $\alpha^{\prime}$-mycolate, and epoxymycolate. Table 1 shows the results of a comparison of the mycolic acid patterns of the type strain of $M$. mageritense and other nonchromogenic rapidly growing mycobacteria $(2,16)$. The mycolate types of $M$. mageritense and $M$. smegmatis were identical.

Mycobacterium species can be differentiated by amplification of the $h s p 65$ gene followed by RFLP analysis $(19,28,31)$. Table 2 shows the DNA fragment sizes generated after digestion with restriction enzymes BstEII and HaeIII for $M$. mageritense and other rapidly growing nonphotochromogenic mycobacteria. Several mycobacterial species exhibit some internal polymorphism of the hsp65 gene (31). This is not the case for the five strains of $M$. mageritense isolated so far; these organisms produce identical fragment patterns (data not shown). The new species can be easily differentiated from $M$. smegmatis by digesting its PCR product with restriction enzyme HaeIII.

The results of the DNA-DNA hybridization studies are shown in Table 3. The levels of DNA-DNA hybridization between $M$. mageritense strains were greater than $70 \%$, and the levels of homology between $M$. mageritense and the majority of the other species tested were less than $28 \%$. M. fortuitum and $M$. peregrinum seemed to be more closely related to $M$. mageritense at the genomic level (DNA-DNA homology values, 15 to $52 \%$ ) than the other species tested. These results indicate that the new strains belong to a novel species.

Previously, we described the usefulness of RFLP analysis of $16 \mathrm{~S}$ rRNA as a complement to DNA-DNA homology data in
(A)

$\begin{array}{lllll}1 & 2 & 3 & 4 & 5\end{array}$
(B)

\section{1}

4 -

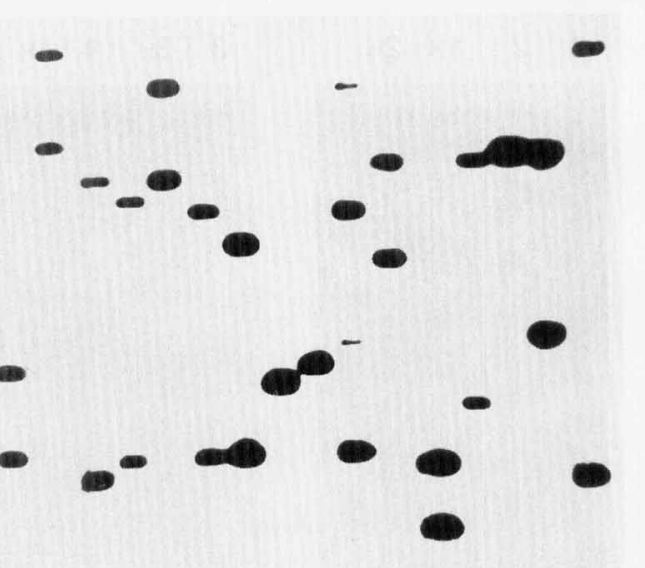

FIG. 2. RFLP patterns of $16 \mathrm{~S}$ rRNA genes from $M$. mageritense strains and other rapidly growing mycobacterial species obtained by using Bam $\mathrm{HI}$ as the restriction enzyme. (A) M. mageritense strains. Lane $1,938^{\mathrm{T}}$; lane 2,1336 ; lane 3, 1470; lane 4, 1635; lane 5, 1636. (B) Rapidly growing mycobacterial species. Lane 6, $M$. mageritense 938 ${ }^{\mathrm{T}}$; lane $7, M$. mucogenicum 283 ; lane $8, M$. brumae CIPT $103465^{\mathrm{T}}$; lane $9, M$. porcinum ATCC $27406^{\mathrm{T}}$; lane 10 , M. senegalense NCTC $_{10956^{\mathrm{T}}}$; lane 11 , M. peregrinum ATCC $14467^{\mathrm{T}}$; lane $12, M$. fortuitum ATCC $6841^{\mathrm{T}}$; lane $13, M$. chelonae ATCC $35752^{\mathrm{T}}$; lane $14, M$. abscessus ATCC $19977^{\mathrm{T}}$; lane 15 , $M$. agri CIPT $1320001^{\mathrm{T}}$; lane 16 , M. chitae CIPT 116000; lane 17, M. smegmatis CIPT 141330010 ; lane 18, M. aurum L1; lane 19, M. gadium ATCC 27726 ${ }^{\mathrm{T}}$; lane 20, M. gilvum Stanford 132; lane 21, M. phlei IMRU 500. Fragment sizes (in kilobase pairs) are indicated on the left of each gel. 

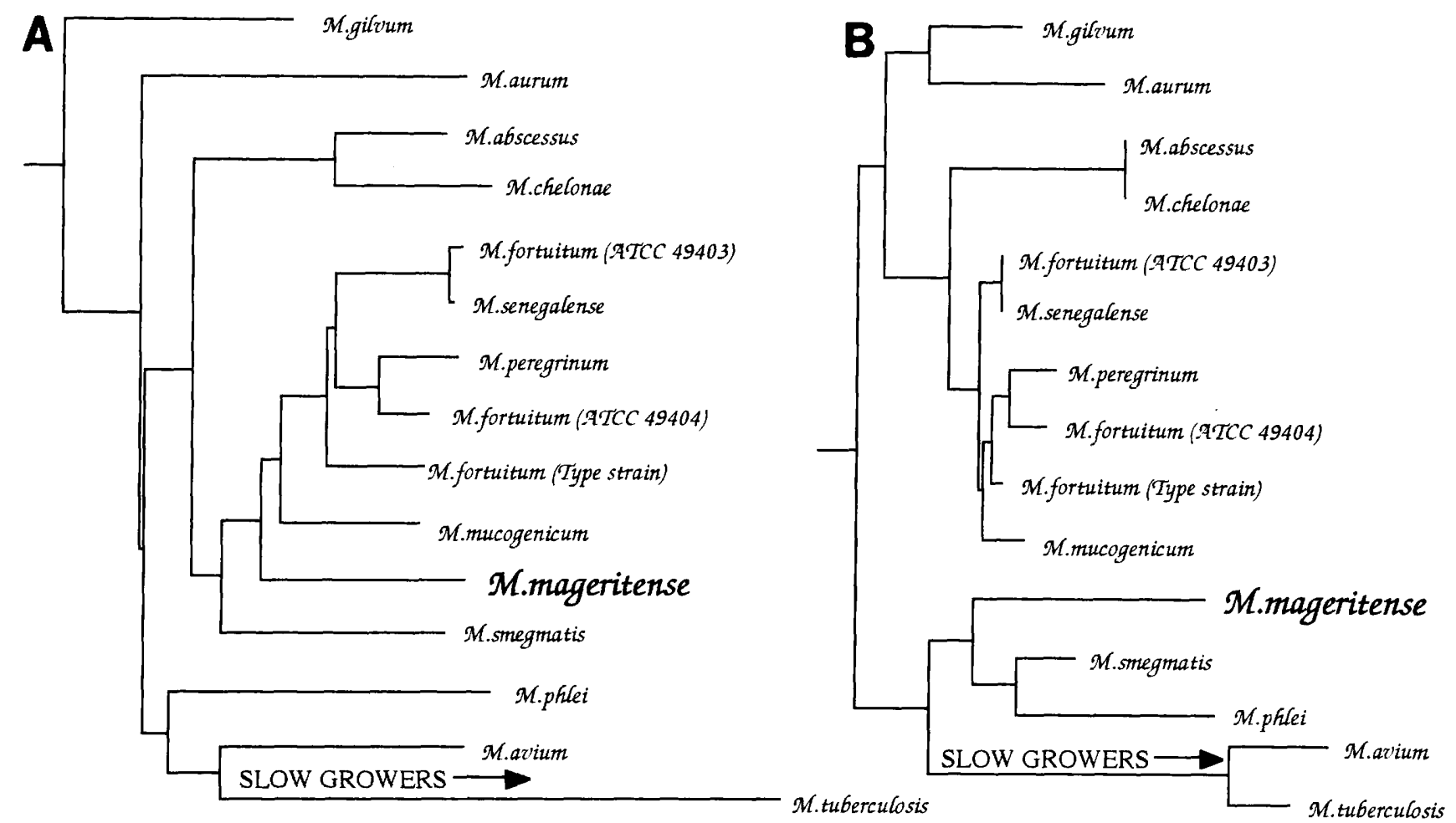

FIG. 3. Phylogenetic position of $M$. mageritense among the rapidly growing mycobacteria as determined by using $\operatorname{sod} A$ gene sequences (A) and $16 \mathrm{~S}$ rRNA sequences (B). Both trees were rooted by using $N$. asteroides as the outgroup and were constructed by using the Fitch-Margoliash algorithm and data from Jukes-Cantor distance matrices.

identification of rapidly growing mycobacterial species (9). Figure 2 shows the RFLP patterns of BamHI-digested genomic DNAs from $M$. mageritense strains and 15 other rapidly growing mycobacterial species; the patterns of different species were different (Fig. 2B), but the patterns of all five $M$. mageritense strains were identical (Fig. 2A). Most of species tested produced a pattern with two bands that indicate the presence of two copies of the 16S rRNA gene. This result has been described as a common feature of rapidly growing mycobacteria $(3,30)$.

We determined the sequence of the 634 nucleotides corresponding to the $5^{\prime}$ region of the $16 \mathrm{~S}$ rRNA gene of the $M$. mageritense strains. This fragment includes main hypervariable regions $\mathrm{A}$ and $\mathrm{B}$.

The $M$. mageritense strains have a $16 \mathrm{~S}$ rRNA sequence with a short helix 18 in hypervariable region $\mathrm{B}$, indicating that they belong to the rapidly growing group $(18,20,27)$ and a short helix 10 in hypervariable region $\mathrm{A}$, indicating that they do not belong to the thermotolerant rapidly growing group $(25,27)$. An alignment of $16 \mathrm{~S}$ rRNA hypervariable region $A$ sequences (E. coli positions 129 to 270 ) revealed that the sequences in this region were identical in the $M$. mageritense strains $\left(938^{\mathrm{T}}, 1336\right.$, 1470,1635 , and 1636) and that the $M$. mageritense sequence differed by at least eight nucleotides from all previously described species-specific sequences (data not shown). An alignment of the $\operatorname{sod} A$ sequences revealed that the sequences of the $M$. mageritense strains were identical and that these sequences differed by more than $11.8 \%$ from all previously described species-specific sequences (data not shown).

Phylogenetic trees constructed by using parts of the $16 \mathrm{~S}$ rRNA and $\operatorname{sod} A$ gene sequences (Fig. 3 ) show that $M$. mageritense belongs to the Mycobacteriaceae and is intermediate in phylogenetic position between the members of the $M$. fortuitum complex and the thermotolerant group of rapid growers, including $M$. smegmatis and $M$. phlei. The 16S rRNA and sodA sequences are sufficiently different from previously described sequences that a discrete phylogenetic line of descent can be constructed, and thus $M$. mageritense is described below as novel species.

Taxonomic description of Mycobacterium mageritense sp. nov. Mycobacterium mageritense (ma.ge.ri.ten'se. L. neut. adj. mageritense, pertaining to Magerit, old [first] Arabic name of Madrid, the source of most of the isolates). Cells are strongly acid-alcohol-fast rods. Colonies on Löwenstein-Jensen medium are smooth, mucoid, and nonphotochromogenic. Visible growth requires 2 to 4 days. Growth occurs at 22, 30, 37, and $45^{\circ} \mathrm{C}$; optimum growth occurs at 30 and $37^{\circ} \mathrm{C}$.

$M$. mageritense is resistant in vitro to hydrazide, cycloserine, capreomycin, pyrazinamide, thiosemicarbazone, and thiophen2-carboxylic acid hydrazide. Variably susceptible to ethambutol. Negative for Tween hydrolysis and for production of thermostable catalase. Positive for arylsulfatase activity at 3 days, nicotinamidase and pyrazinamidase activities, and use of mannitol as a sole carbon source. Variable in tests for nitrate reductase, several amidases, utilization of citrate and inositol as sole carbon sources, and iron uptake. Synthesizes $\alpha$-mycolate, $\alpha^{\prime}$-mycolate, and epoxymycolate.

The results of DNA analyses (DNA-DNA hybridization, RFLP analysis of 16S rRNA genes, PCR-RFLP analysis of the $h s p 65$ gene, sequences of sodA and $16 \mathrm{~S}$ rRNA genes) show that $M$. mageritense is a distinct genomic species that is closely related to $M$. fortuitum and $M$. peregrinum at the DNA homology level. The 16S rRNA and $\operatorname{sod} A$ gene sequences of $M$. mageritense are unique.

Type strain 938 was isolated from human sputum; a culture of this strain has been deposited in the Collection de Bacteries de L'Institut Pasteur as strain CIP 104973. 
Characteristics which differentiate $M$. mageritense from related mycobacteria. $M$. mageritense can be differentiated from the closely related species $M$. fortuitum by its growth at $45^{\circ} \mathrm{C}$ and by its use of mannitol as a sole carbon source and from $M$. smegmatis by its growth on MacConkey agar without crystal violet. $M$. mageritense differs from other rapidly growing mycobacteria by the presence of heat-labile catalase activity and by the lack of heat-resistant catalase activity.

A unique PCR-RFLP pattern for the $h s p 65$ gene and unique 16S rRNA and sodA sequences characterize $M$. mageritense. The phylogenetic position of $M$. mageritense, based on the results of an evaluation of $16 \mathrm{~S}$ rRNA and sodA sequences, is with the rapid growers, between members of the $M$. fortuitum complex and the thermotolerant group, including $M$. smegmatis. Levels of DNA homology (greater than 70\%) confirm the homogeneity of the $M$. mageritense strains and that this organism differs from other rapidly growing mycobacteria.

\section{ACKNOWLEDGMENTS}

We thank M. Garcia-Barcelo for performing the mycolic acid analysis and V. Ausina for kindly providing some of the mycobacterial strains.

This research was supported by grants 89/0128 and 94/0051-02 from the Spanish Fondo de Investigaciones Sanitarias de la Seguridad Social.

\section{REFERENCES}

1. Amann, R. I., W. Ludwig, and K.-H. Schleifer. 1995. Phylogenetic identification and in situ detection of individual microbial cells without cultivation. Microbiol. Rev. 59:143-169.

2. Ausina, V., M. Luquin, M. García-Barceló, M. A. Lanéelle, V. Lévy-Frébault F. Belda, and G. Prats. 1992. Mycobacterium alvei sp. nov. Int. J. Syst. Bacteriol. 42:529-535.

3. Bercovier, H., O. Kafri, and S. Sela. 1986. Mycobacteria possesses a surprisingly small number of ribosomal RNA genes in relation to the size of their genome. Biochem. Biophys. Res. Commun. 136:1136-1141.

4. Bradford, M. 1976. A rapid and sensitive method for the quantitation of microgram quantities of protein utilizing the principle of protein-dye binding. Anal. Biochem. 72:248-254.

5. Bull, T. J., D. C. Shanson, and L. C. Archard. 1995. Rapid identification of mycobacteria from AIDS patients by capillary electrophoresis profiling of amplified SOD gene. J. Clin. Pathol. Mol. Pathol. 48:m124-m132.

6. Butiaux, R., H. Beerns, and A. Tacquet. 1973. Techniques en Bacteriologie, vol. 2. Mycobactéries. Editions Medicales Flammaron, Paris, France.

7. Butler, W. R., K. C. Jost, and J. O. Kilburn. 1991. Identification of mycobacteria by high-performance liquid chromatography. J. Clin. Microbiol 29:2468-2472.

8. Daffé, M., M. A. Lanéelle, C. Asselineau, V. Lévy-Frébault, and H. David. 1983. Intérèt taxonomic del acides gras des mycobactéries: proposition d'une méthode d'analyse. Ann. Inst. Pasteur Microbiol. 134B:241-256.

9. Domenech, P., M. C. Menéndez, and M. J. García. 1994. Restriction fragment length polymorphism of 16S rRNA genes in the differentiation of fas growing mycobacterial species. FEMS Microbiol. Lett. 116:19-24.

10. Goodfellow, M., and D. E. Minnikin. 1984. Circumscription of the genus, p 1-24. In G. P. Kubica and L. G. Wayne (ed.), The mycobacteria. A sourcebook, part A. Marcel Dekker, Inc., New York, N.Y.

11. Hermans, J., C. Martin, G. N. M. Huijberts, T. Goosen, and J. A. M. de Bont 1991. Transformation of Mycobacterium aurum and Mycobacterium smegmatis with the broad host-range Gram negative cosmid vector pJRD215. Mol. Microbiol. 5:1561-1566.

12. Kirschner, P., A. Teske, K.-H. Schröder, R. M. Kroppenstedt, J. Wolters, and E. C. Böttger. 1992. Mycobacterium confluentis sp. nov. Int. J. Syst. Bacteriol. 42:257-262.

13. Kirschner, P., B. Springer, U. Vogel, A. Meier, A. Wrede, M. Kiekenbeck, F. C. Bange, and E. C. Böttger. 1993. Genotypic identification of mycobacteria by nucleic acid sequence determination: report of a 2-year experience in a clinical laboratory. J. Clin. Microbiol. 31:2882-2889.

14. Lévy-Frébault, V., M. Daffé, K. S. Goh, M. A. Lanéelle, C. Asselineau, and H. L. David. 1983. Identification of Mycobacterium fortuitum and Mycobacterium chelonae. J. Clin. Microbiol. 17:744-752.

15. Lévy-Frébault, V., and F. Portaels. 1992. Proposed minimal standards for the genus Mycobacterium and for the description of slowly growing Mycobacterium species. Int. J. Syst. Bacteriol. 42:315-323.

16. Luquín, M., V. Ausina, F. López Calahorra, F. Belda, M. García-Barceló, C Celma, and G. Prats. 1991. Evaluation of practical chromatographic proce- dures for identification of clinical isolates of mycobacteria. J. Clin. Microbiol. 29:120-130.

17. Luquín, M., M. A. Lanéelle, V. Ausina, M. García-Barceló, F. Belda, C Alonso, and G. Prats. 1991. Distribution of a novel mycolic acid in species of the genus Mycobacterium. Int. J. Syst. Bacteriol, 41:390-394.

18. Pitulle, C., M. Dorch, J. Kazda, J. Wolters, and E. Stackebrandt. 1992. Phylogeny of rapidly growing members of the genus Mycobacterium. Int. J. Syst. Bacteriol. 42:337-343.

19. Plikaytis, B. B., B. D. Plikaytis, M. A. Yakrus, W. R. Butler, C. L. Woodley, V. A. Silkox, and T. M. Shinnick. 1992. Differentiation of slowly growing Mycobacterium species, including Mycobacterium tuberculosis, by gene amplification and restriction fragment length polymorphism analysis. J. Clin. Microbiol. 30:1815-1822.

20. Rogall, T. J. Wolters, T. Flohr, and E. C. Böttger. 1990. Towards a phylogeny and definition of species at the molecular level within the genus Mycobacterium. Int. J. Syst. Bacteriol. 40:323-330.

21. Selander, R. K., D. A. Caugent, H. Ochman, J. M. Musser, M. N. Gilmour, and T. S. Whittam. 1986. Methods of multilocus enzyme electrophoresis for bacterial population genetics and systematics. Appl. Environ. Microbiol. 51:873-884.

22. SEQNET Computing Facility. 1989. PHYLIP analysis package (version 3.2) Cladistics 5:164-166.

23. Silcox, V. A., R. C. Good, and M. M. Floyd. 1981. Identification of clinically significant Mycobacterium fortuitum complex isolates. J. Clin. Microbiol. 14: $686-691$

24. Sommers, H. M., and R. C. Good. 1985. Mycobacterium, p. 216-248. In E. H Lennette, A. Balows, W. J. Hausler, and H. J. Shadomy (ed.), Manual of clinical microbiology, 4th ed. American Society for Microbiology, Washington, D.C.

25. Springer, B., L. Stockman, K. Teschner, G. D. Roberts, and E. C. Böttger 1996. Two-laboratory collaborative study on identification of mycobacteria: molecular versus phenotypic methods. J. Clin. Microbiol. 34:296-303.

26. Stackebrandt, E., and B. M. Goebel. 1994. Taxonomic note: a place fo DNA-DNA reassociation and 16S rRNA sequence analysis in the present species definition in bacteriology. Int. J. Syst. Bacteriol. 44:846-849.

27. Stahl, D. A., and J. W. Urbance. 1990. The division between fast- and slow-growing species corresponds to natural relationships among the mycobacteria. J. Bacteriol. 172:116-124.

28. Steingrube, V. A., J. L. Gibson, B. A. Brown, Y. Zhang, R. W. Wilson, M. Rajagopalan, and R. J. Wallace. 1995. PCR amplification and restriction endonuclease analysis of a 65 -kilodalton heat shock protein gene sequence for taxonomic separation of rapidly growing mycobacteria. J. Clin. Microbiol. 33:149-153.

29. Suzuki, Y., A. Nagata, Y. Ono, and T. Yamada. 1988. Complete nucleotide sequence of the 16S rRNA gene of Mycobacterium bovis BCG. J. Bacteriol 170:2886-2889.

30. Suzuki, Y., and T. Yamada. 1988. Study on rRNA genes in Mycobacterium smegmatis. Microbiol. Immunol. 32:1259-1262.

31. Telenti, A., F. Marchesi, M. Balz, F. Bally, E. C. Böttger, and T. Bodmer. 1993 Rapid identification of mycobacteria to the species level by polymerase chain reaction and restriction enzyme analysis. J. Clin. Microbiol. 31:175-178.

32. Vestal, A. L. 1975. Procedures for the isolation and identification of mycobacteria. Publication (CDC) 76-8230. Centers for Disease Control, Atlanta, Ga.

33. Wayne, L. G., H. C. Engbaeck, H. W. B. Engel, S. Froman, W. Gross, J. Hawkins, W. Käpler, A. G. Karlson, H. H. Kleeberg, I. Krasnow, G. P Kubica, C. McDurmont, E. E. Nel, S. R. Pattyn, K. H. Schröder, S. Showalter, I. Tarnok, M. Tsukamura, B. Vergman, and E. Wolinsky. 1974 Highly reproducible techniques for use in systematic bacteriology in the genus Mycobacterium: test for pigment, urease, resistance to sodium chloride, hydrolysis of Tween 80 , and $\beta$-galactosidase. Int. J. Syst. Bacteriol. 24:412-419.

34. Wayne, L. G., H. W. B. Engel, C. Grassi, W. Gross, J. Hawkins, P. A. Jenkins W. Käpler, H. H. Kleeberg, I. Krasnow, E. E. Nel, S. R. Pattyn, P. A Richards, S. Showalter, M. Slosarek, I. Szabo, I. Tarnok, M. Tsukamura, B Vergman, and E. Wolinsky. 1976. Highly reproducible techniques for use in systematic bacteriology in the genus Mycobacterium: test for niacin and catalase and for resistance to isoniazid, thiophen-2-carboxylic acid hydrazide, hydroxylamine, and p-nitrobenzoate. Int. J. Syst. Bacteriol. 26:311-318.

35. Wayne, L. G., and G. A. Diaz. 1986. A double staining method for differentiating between two classes of mycobacterial catalase in polyacrylamide electrophoresis gels. Anal. Biochem. 157:89-92.

36. Wayne, L. G., and G. P. Kubica. 1986. The mycobacteria, 1435-1457. In P. H. A. Sneath, N. S. Mair, M. E. Sharpe, and J. G. Holt (ed.), Bergey's manual of systematic bacteriology, vol. 2. The Williams \& Wilkins Co., Baltimore, Md.

37. Zhang, Y., R. Lathigra, T. Garbe, D. Catty, and D. B. Young. 1991. Genetic analysis of superoxide dismutase, the 23 kilodalton antigen of Mycobacterium tuberculosis. Mol. Microbiol. 5:381-391.

38. Zolg, J. W., and S. Philippi-Schulz. 1994. The superoxide dismutase gene, a target for detection and identification of mycobacteria by PCR. J. Clin Microbiol. 32:2801-2812. 